\title{
Applications of gut microbiota in patients with hematopoietic stem-cell transplantation
}

\author{
Jifeng Yu ${ }^{1,2+} \mathbb{B}$, Hao Sun ${ }^{3+}$, Weijie Cao ${ }^{1}$, Lijie Han ${ }^{1}$, Yongping Song ${ }^{4}$, Dingming Wan ${ }^{1 *}$ and Zhongxing Jiang ${ }^{1 *}$
}

\begin{abstract}
Studies of the gut microbiota (GM) have demonstrated the close link between human wellness and intestinal commensal bacteria, which mediate development of the host immune system. The dysbiosis, a disruption of the microbiome natural balance, can cause serious health problems. Patients undergoing allogeneic hematopoietic stem cell transplantation (allo-HSCT) may cause significant changes in GM due to their underlying malignancies and exposure to extensive chemotherapy and systemic antibiotics, which may lead to different disorders. There are complex and multi-directional interactions among intestinal inflammation, GM and immune reactivity after HSCT. There is considerable effect of the human intestinal microbiome on clinical course following HSCT. Some bacteria in the intestinal ecosystem may be potential biomarkers or therapeutic targets for preventing relapse and improving survival rate after HSCT. Microbiota can be used as predictor of mortality in allo-HSCT. Two different strategies with targeted modulation of GM, preemptive and therapeutic, have been used for preventing or treating GM dysbiosis in patients with HSCT. Preemptive strategies include enteral nutrition (EN), prebiotic, probiotic, fecal microbiota transplantation (FMT) and antibiotic strategies, while therapeutic strategies include FMT, probiotic and lactoferrine usages. In this review, we summarize the advance of therapies targeting GM in patients with HSCT.
\end{abstract}

Keywords: Targeted modulation therapy, Gut microbiota, Hematopoietic stem cell transplantation (HSCT)

\section{Introduction}

Thousands of different species of micobiome are colonized at different sites of human body and play a key role in maintaining our health or promoting disease [1]. Studies of the gut microbiota (GM) have demonstrated the close link between human wellness and intestinal commensal bacteria, which mediate development of the host immune system [2]. The dysbiosis, a disruption of the microbiome natural balance, can cause serious health problems $[3,4]$. Patients undergoing allogeneic hematopoietic stem cell transplantation (allo-HSCT) may cause significant changes in GM due to their underlying malignancies and exposure to extensive chemotherapy and

\footnotetext{
*Correspondence: wwddmm@vip.sina.com; jiangzx@zzu.edu.cn

${ }^{\dagger}$ Jifeng Yu and Hao Sun contributed equally to this work

${ }^{1}$ Department of Hematology, The First Affiliated Hospital of Zhengzhou

University, Zhengzhou 450052, China

Full list of author information is available at the end of the article
}

systemic antibiotics, which may lead to biological disorders. Studies have shown that there are complex and multi-directional interactions among intestinal inflammation, GM and immune reactivity after HSCT. There is mounting evidence for the considerable effect of the human intestinal microbiome on clinical course following HSCT [5-7]. The abundance or presence of some bacteria in the intestinal ecosystem may be potential biomarkers or therapeutic targets for preventing relapse and improving survival rate after HSCT [8]. Most recent study showed that microbiota can be used as predictor of mortality in allo-HSCT [9]. Many studies have showed that targeted modulation of GM in patients with HSCT has potential therapeutic implications [10]. In this review, we summarize the advance of therapies targeting GM in patients with HSCT.

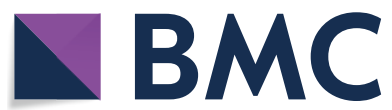

(c) The Author(s) 2020. This article is licensed under a Creative Commons Attribution 4.0 International License, which permits use, sharing, adaptation, distribution and reproduction in any medium or format, as long as you give appropriate credit to the original author(s) and the source, provide a link to the Creative Commons licence, and indicate if changes were made. The images or other third party material in this article are included in the article's Creative Commons licence, unless indicated otherwise in a credit line to the material. If material is not included in the article's Creative Commons licence and your intended use is not permitted by statutory regulation or exceeds the permitted use, you will need to obtain permission directly from the copyright holder. To view a copy of this licence, visit http://creativecommons.org/licenses/by/4.0/. The Creative Commons Public Domain Dedication waiver (http://creativecommons.org/publicdomain/zero/1.0/) applies to the data made available in this article, unless otherwise stated in a credit line to the data. 


\section{Mechanism of gut microbiota in graft versus host disease (GvHD)}

Gut GvHD is the result of conditioning toxicity and immune activation associated with injury of the stemcell compartments along with Paneth and goblet cells in the intestinal mucosa [11]. This leads to increased intestinal permeability, inflammation, and reduction of the mucous membrane $[12,13]$. The mucus layer produced by goblet cells acts as a physical barrier in the gut and regulates the relationship between the microbiota and the host [14]. Intestinal epithelial cells, dendritic cells, and macrophages express pattern recognition receptors, such as Toll-like receptors, which can recognize microbe-associated molecular patterns. Activation of these receptors triggers proinflammatory cytokine response and presents antigens to regulatory $\mathrm{T}$ cells (Tregs). Activation of Tregs conveys tolerance towards commensal bacteria [14]. Gut bacteria produce Butyrate and other short-chain fatty acid (SCFA), which exert anti-inflammatory effects on the macrophages and the dendritic cells through inhibiting histone deacetylase (HDAC), inhibiting NF- $\mathrm{KB}$ signaling and increasing IL-10 expression [15]. Metabolomics analysis of human acute graft-versus-host disease reveals changes in host and microbiota-derived metabolites [16]. Most recent study revealed that Butyrate was significantly decreased in all gastro-intestinal (GI) acute GvHD (aGVHD) stages. Specific microbiota and metabolic alterations were associated with aGVHD severity and may be useful for diagnostic and pathophysiologic purposes [17].

Segmented filamentous bacteria can penetrate the mucus layer and interact with epithelial cells, inducing the differentiation of $\mathrm{T}$ helper 17 (Th17) cells [18]. Th17 cells are specialized in responses to extracellular bacteria and fungi by secretion of cytokines such as IL-17A, IL-17F, IL-21, and IL-22 [18]. The cytokines produced by Th17 cells induce secretion of antimicrobial peptides such as the $\alpha$-defensins and RegIII $\gamma$ by the Paneth cells [14]. Patients with hematological diseases requiring HSCT undergo extensive preconditioning chemotherapy as well as antibiotic or antifungal treatments. Although antibiotic treatment in HSCT patients is essential in many patients to avoid bacterial infections, these interventions result in the disruption of the gut microbiota and its equilibrium and can cause additional gastrointestinal damage. Studies have shown that there is a high risk of bacterial infection during transplantation, and subsequent GvHD and low GM diversity are closely associated with transplant related mortality [19, 20]. Alteration of the intestinal microbiota by broadspectrum antibiotic use correlates with the occurrence of intestinal GvHD [21]. GvHD occurs in a large number of patients receiving allo-HSCT, resulting in a mortality rate of up to $30 \%$ [22].

Extensive studies of monitoring microbiome alterations have been done, especially regarding the GM and the GvHD in patients with HSCT [7-10, 23]. The most recent study showed patterns of microbiota disruption during allo-HSCT were similar across transplantation centers and geographic locations. Patterns were characterized by loss of diversity and domination by single taxa. Higher diversity of intestinal microbiota at the time of neutrophil engraftment was associated with lower mortality [9]. The microbiota can be used as predictor of mortality in allo-HSCT [10], and the constitution of the intestinal microbiota at neutrophil engraftment and GM score can predict the development of aGvHD following myeloablative allo-HSCT [24, 25]. These results supported the idea for modulation of the GM in patients with HSCT.

\section{Modulation of the GM in HSCT}

After the confirmation of the strong impact of the GM on all aspects of HSCT, modulating GM composition in order to improve clinical outcomes has been proposed following different clinical trials. The main interventions described in the literature included two different potential strategies, preemptive and therapeutic, both of which have been used for preventing or treating GM dysbiosis during HSCT. Preemptive strategies include enteral nutrition (EN), prebiotic, probiotic, fecal microbiota transplantation (FMT) and antibiotic strategies, while therapeutic strategies include FMT, probiotic and lactoferrine usages [10] (Fig. 1).

\section{Nutritional supplementation in HSCT}

Nutrition support for patients includes two different kinds of options, EN and parenteral nutrition (PN). EN is a kind of nutritional support that provides nutrients and other nutrients needed by metabolism through the gastrointestinal tract. Meanwhile, PN is through intravenous injection into the blood circulation to supplement nutrition.

Many studies have confirmed the connection between nutrition and the human microbiome in maintaining human health [26-30]. Traditionally, the first nutritional approach in post-HSCT patients is parenteral nutrition $(\mathrm{PN})$, which is associated with several clinical adverse effects, supporting EN as a preferential alternative. The effect of PN and starvation on the intestinal ecosystem during HSCT has been studied and the results showed the decreased microbial richness and diversity [31, 32]. PN has been associated with the loss of commensal bacteria belonging to the genus Blautia and induces gut mucosal atrophy, promoting bacterial translocation and altering SCFA production [33-36]. Clinical data show 


\section{Depiction of FMT mechanism}

a

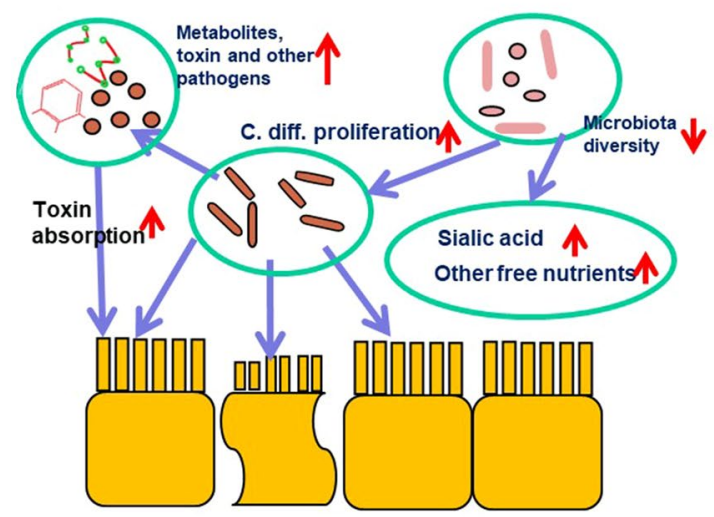

b

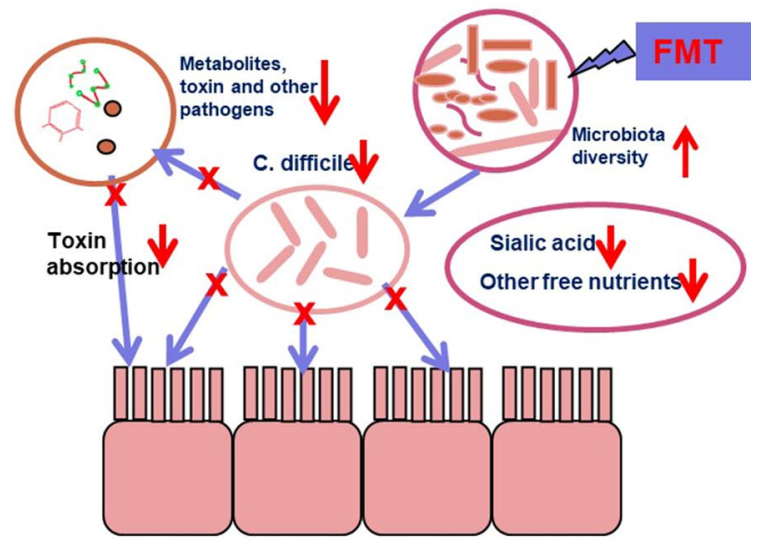

Fig. 1 Depiction of FMT mechanism. a HSCT and related procedures caused toxin secretion and intestinal epithelial cells damage. $\mathbf{b}$ FMT treatment made the microbiota diversity and intestinal epithelial cells recovery

that EN is associated with better outcomes in terms of survival, infection, and aGvHD [37-40]. Recent studies have showed that EN is a feasible and nutritionally adequate method of nutritional support for children undergoing allo-HSCT. EN can protect children undergoing allo-HSCT from blood stream infections [41] and promote the recovery of gut microbiome homeostasis [42]. In patients with EN, structural and functional probiotic GM distribution is rapidly restored after HSCT, which may reduce the risk of systemic infection and GvHD onset [42]. However, more studies are needed to further explore the role of the type of nutritional support in preserving GM during HSCT. These nutritional supports include applications of prebiotics, antibiotics, lactoferrin and probiotics.

\section{Prebiotics}

The first commonly used nutrition support option is prebiotics. Prebiotics are defined as 'a substrate which is selectively utilized by host microorganisms conferring a health benefit' [43]. This term usually refers to indigestible carbohydrates, such as dietary fibers, which are fermented in the colon by commensal bacteria to modify the microbiota and produce metabolites with potential immunomodulatory effects [44]. Examples of these fibers include resistant starches, fructooligosaccharides (including inulin), and galacto-oligosaccharides, which are found in a variety of foods including onions, oats, garlic, asparagus, and human milk. Different nutritional strategies have been explored in patients with HSCT in order to modify the GM. Tavil et al. utilized a diet richer in fibre in a patient in the pre-HSCT period, which correlated with earlier neutrophil engraftment and a shorter duration of febrile neutropenia [45]. Preemptive enteral supplementation with glutamine, fiber and oligosaccharide strategy is an effective supportive therapy to decrease the severity of mucosal damage in HSCT [46]. Currently, there is only one ongoing clinical trial using prebiotic to promote a healthy gut microbiome in pediatric HSCT recipients in the United States (NCT04111471).

Prebiotics are metabolized by selected intestinal microorganisms and produce a variety of compounds through fermentation, including SCFAs butyrate, acetate and propionate. Several important studies highlighting the mechanism of prebiotics effect on gut mucosa and host immune response mediated by the intestinal microbiota [47]. SCFAs affect the host by (i) serving as a direct substrate for intestinal epithelial metabolism and maintenance of the mucosal barrier, (ii) affecting immune cell signaling and proliferation, (iii) altering epigenetic modifications, (iv) impacting microbial-microbial and microbial-host interactions, and (v) influencing chemotherapy efficacy and toxicity [47].

Butyrate and related SCFAs are major products of prebiotic metabolism. SCFAs can change the signaling of host immune cells: butyrate in the colonic lumen can increase the proliferation of host Tregs [48] and activate dendritic cells through signaling via chemokine G-protein-coupled receptors [49]. Thus it causes the differentiation of naive $\mathrm{T}$ cells into Tregs functions to suppress other immune cells that may induce inflammation. 
SCFAs can also act as HDAC inhibitors that change DNA structure and transcription, altering leukocytes and potentially affecting cancer [50] and infection risk [51]. Epigenetic changes have been increasingly implicated in hematologic malignancies like acute myeloid leukemia (AML) and may be affected by the GM. Prebiotics not only impact the risk of infection and GvHD, but also may influence chemotherapy efficacy and toxicity through cellular signaling pathways influenced by SCFA production in patients with cancer [52].

Emerging strategies for prebiotics have been developed in recent years by investigating non-fiber dietary supplements, such as vitamin $\mathrm{A}$, on both microbiota composition and HSCT outcomes [43, 53]. One study showed that vitamin A levels in patients 30 days after HSCT predicted the incidence of GvHD and it may lead to the differentiation of naive T-cells into Tregs rather than Th17 cells, facilitating mucosal tolerance and improving mucosal barrier integrity [54]. Meanwhile, commensal bacteria may inhibit retinoid metabolism in the intestinal epithelium, reduce IL-22 levels and prevent dysbiosis [55]. The increased IL-22 level in children with GI aGvHD further supports the relationship between retinoic acid metabolism, IL-22 level and GvHD [56]. Table 1 summarizes the main on-going studies regarding dietary nutrition in HSCT. Especially, there are one completed (NCT03039257) and two ongoing clinical trials (NCT03202849, NCT03719092) with vitamin A supplementation in patients with HSCT (Table 1), and another ongoing trial directly administering IL-22 $\mathrm{Fc}$ as a potential therapy to attenuate GI GvHD (NCT02406651).

\section{Lactoferrin}

Lactoferrin, a glycoprotein of transferrin family, is an iron-binding protein with pleiotropic functions, such as antianemic, antimicrobial, anti-inflammatory, immunoregulatory, antioxidant, and anti-cancer activity, and is also involved in intestinal epithelial regeneration and iron homeostasis [57]. Recently, lactoferrin has been used as new specific molecule in dysbiosis prevention. Lactoferrin and $\mathrm{N}$-terminal peptide-derivatives have been studied in preclinical models, and can reduce bacterial translocation, improving GM eubiosis [58, 59]. Administration of lactoferrin in an HSCT patient showed that symptoms of gut GvHD disappeared soon after lactoferrin therapy was started [60]. Introduction of probiotics with a regimen containing bovine lactoferrin for preterm infants in New Zealand has been associated with significant reductions in necrotizing enterocolitis (NEC) and late onset sepsis [61]. A pooled analysis of individual patient data from two randomized controlled trials demonstrated bovine lactoferrin supplementation protects against late-onset sepsis in infants $<1500 \mathrm{~g}$, especially among infants not receiving human milk [62]. Study by using probiotic and lactoferrin prebiotic were administered in mice showed both Clostridioides difficile inoculation and treatment with vancomycin or fidaxomicin reduced microbiota diversity; however, dysbiosis associated with fidaxomicin was milder than with vancomycin [63]. The use of lactoferrin, or short peptide derivatives that retain the cationic $\mathrm{N}$-terminal moiety that is essential for the anti-microbial and anti-inflammatory activity, may prove to be a promising versatile class of agents for managing the complications that arise from HSCT [64]. Lactoferrin has also been used for many other different clinical applications and has more potential perspectives on its prophylactic and therapeutic applications in the future [57]. Additionally, lactoferrin offers a promising biodegradable well tolerated material that could be exploited both as an active therapeutic and drug nanocarrier. Lactoferrin-based nanocarriers have been demonstrated as efficient platforms for delivery of anti-parkinsonian, anti-Alzheimer, anti-viral drugs, immunomodulatory and bone engineering applications [65].

\section{Probiotics}

Another commonly used nutrition support option is probiotics. Probiotics consist of traditional and commonly eaten foods, and are defined by the Food and Agriculture Organization of the United Nations (FAO) and the World Health Organization (WHO) as live microorganisms which when administered in adequate amounts, confer a health benefit on the host' [66]. A probiotic-rich diet prior to HSCT is associated with earlier neutrophil engraftment and a shorter duration of febrile neutropenia [45]. However, in a randomized probiotic enteric regimen trial, supplementation of Lactobacillus rhamnosus GG in patients with allo-HSCT showed no significant change in GM or protection against GvHD [67]. In another phase II trial, which lacked a control group, prophylactic use of Lactobacillus brevis CD2 lozenges appeared to reduce the incidence, duration and severity of oral mucositis [68]. Recent study supports the safe use of probiotics in a high-risk population of pediatric HSCT patients with compromised intestinal mucosal integrity [69].

On the other hand, for immune compromised patients with related symptoms and some changes in intestinal permeability, there are some concerns regarding the safety of probiotics administration. For instance, it has been reported bacteremia and sepsis caused by pathogens normally considered being probiotics [70], and infection resulted in meningitis in one report of a child undergoing HSCT [71]. However, data analysis of HSCT patients supports the safety of probiotics, suggesting that organisms frequently included in over-the-counter probiotics are a rare cause of bacteremia after HSCT [72], 


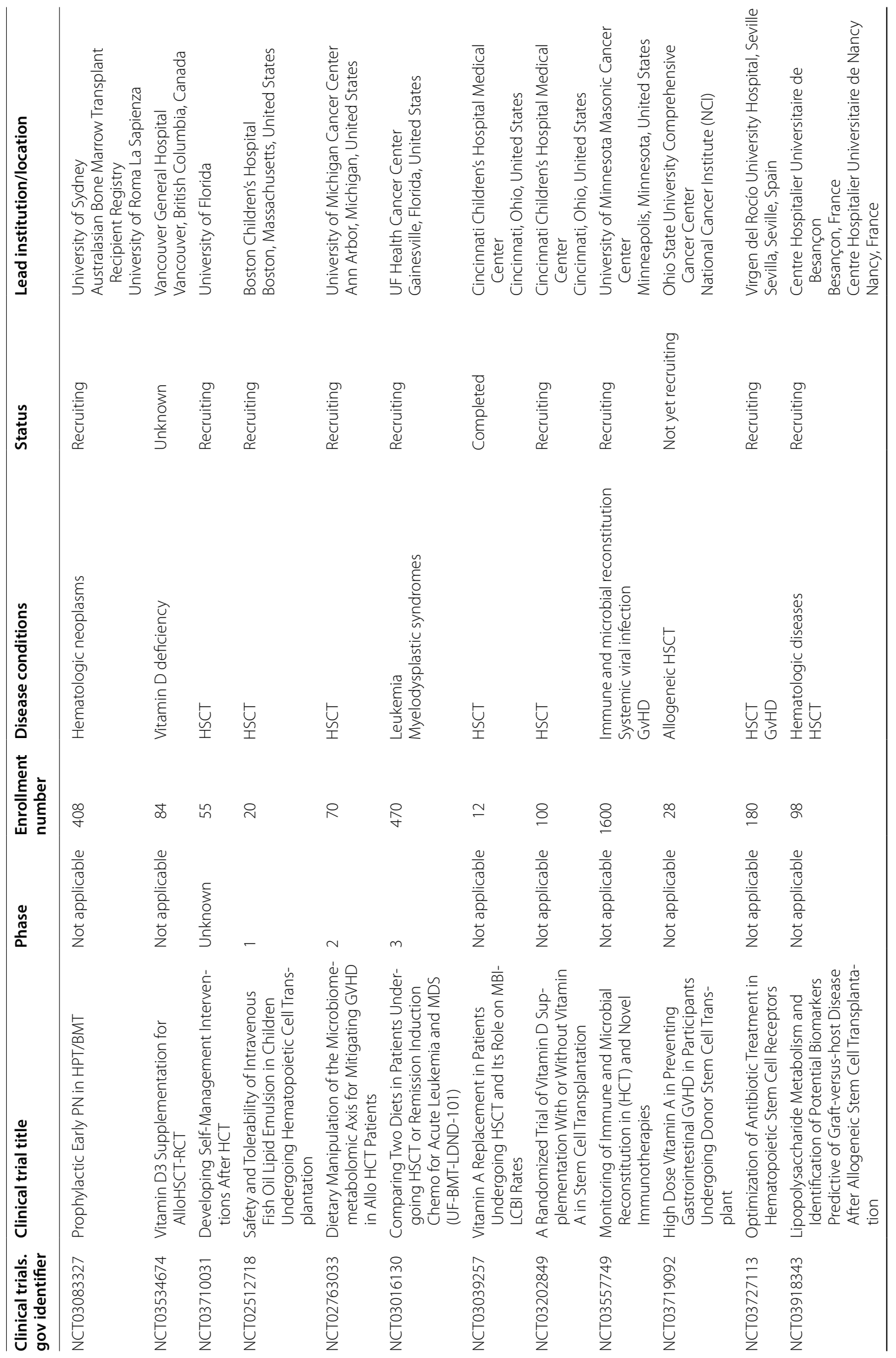




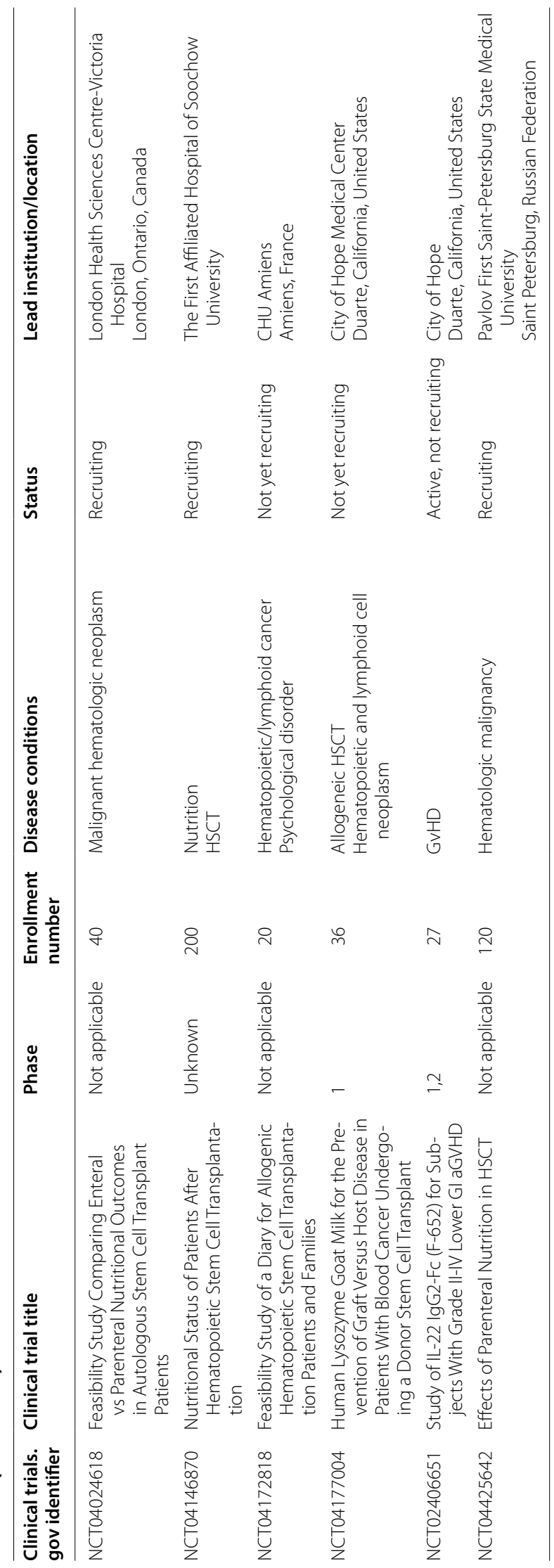


indicating the safety and feasibility of probiotic Lactobacillus plantarum in children and adolescents receiving HSCT treatment, without associated bacteremia or adverse events [73].

\section{FMT}

FMT refers to the infusion of feces from healthy donors into the gastrointestinal tract of recipient patients with dysbiotic GM. FMT was first found to be effective for the treatment of recurrent Clostridium difficile infections (rCDI). It is currently being evaluated in many different fields, including HSCT [74]. It is considered as the "ultimate probiotics" by some authors because it directly changes the intestinal microbial composition of the host, thus restoring eubiosis and intestinal homeostasis $[75,76]$. Table 2 summarizes the main on-going studies regarding FMT and microbiota in HSCT (Table 2). The source of fecal materials can be either healthy donors or the patient themselves. Clinical findings point toward a beneficial effect of FMT to improve GvHD and HIVrelated outcomes through the engraftment of beneficial donor bacteria, notably those producing anti-inflammatory metabolites [77]. Clinical trials results indicate that empiric third-party FMT after allo-HCT appears to be feasible, safe, and associated with expansion of recipient microbiome diversity [78].

Recent study demonstrated that donor FMT can ameliorates intestinal GvHD in allo-HSCT recipients [79], which is an effective and safe method for the treatment of refractory diarrhea after allo-HSCT [80]. A singlecenter pilot study showed that Longitudinal analysis of fecal microbiome and metabolites after HSCT identified butyrate and indole as potential surrogate markers for microbial diversity and specific taxa. However, further studies are needed to ascertain whether fecal metabolites can be used as biomarkers of acute intestinal GvHD or bacteremia after HSCT [81]. Furthermore, in patients carrying or infected by multidrug-resistant bacteria, FMT is an effective and safe decolonization strategy, even in those with hematologic malignancies undergoing HSCT [82]. FMT in the treatment of intestinal steroidresistant GvHD have been evaluated with very promising results $[83,84]$.

Recent studies have demonstrated the early GM signature of aGvHD in children given allo-HSCT for hematological disorders. Children developing GI aGvHD had a dysbiotic GM layout before HSCT occurred. This putative aGvHD-predisposing ecosystem state was characterized by (i) reduced diversity, (ii) lower Blautia content, (iii) increase in Fusobacterium abundance. At time of engraftment, the GM structure underwent a deep rearrangement in all patients and reacquired a eubiotic configuration from day 30 . This specific GM signature before
HSCT predictive of subsequent GI aGvHD occurrence may be useful for GM-based stratification of the risk of developing aGvHD in children undergoing HSCT, potentially also useful to identify patients benefiting from prophylactic FMT [85].

Due to the genetic similarity and shared environment, a related FMT donor may have a GM composition closer to the recipient's before the HSCT-induced dysbiosis. However, related FMT donors need time to screen, collect, and process, whereas unrelated healthy FMT donors fecal material can be collected and stored frozen in a stool bank for use when needed [76]. Donor screening is a key factor in the safety of the procedure in order to prevent iatrogenic infectious diseases potentially transmittable to the recipient [75]. Different ways of administering FMT, such as colonoscopy, esophago-gastro-duodenoscopy, nasogastric or naso-duodenal tube, enema, and oral capsule can be used without superiority over each other [86]. Oral capsule seems to maintain the efficacy and safety of other routes, and is less invasive for the patient [87], with the feasibility for a substantial number of capsules to achieve the necessary microbial load [88]. Although it's important to use different methods to treat the HSCTinduced dysbiosis, maintaining Bacteroides during alloHSCT is the best practice strategy for the prevention of aGvHD [89]. Different options provide promising and practical results in clinical treatment. However, there is no evidence that prophylactic FMT improves clinical outcomes, and larger clinical trials are needed to further determine the standard treatment procedure for aGVHD patients using FMT.

\section{Mechanism of FMT}

Although FMT has been successfully used to treat diseases including GvHD and other recurrent or refractory Clostridium difficile infection (rCDI) [90], the mechanisms by which it exerts its therapeutic effects have not yet been fully elucidated. Most researchers leaned to the competitive exclusion of the pathogen with the microbiota outcompeting $\mathrm{C}$. difficile for nutrients and creating an environment that is unfavorable for its growth [91]. The dysbiosis that caused by HSCT and related procedures (conditioning regimen, antibiotic exposure, diet, anti-acid prophylaxis) as a combination of upsetting events, which profoundly modify the GM structure, leading to disruption of healthy environment for microbiota. The efficacy of FMT for rCDI through competitive exclusion is thought to occur in part through the modulation of bile-salt metabolism, which affects C. difficile spore germination. Also, FMT may also exert its therapeutic effect by increasing sialic-acid utilization by commensal bacteria, thus depriving $\mathrm{C}$. difficile 


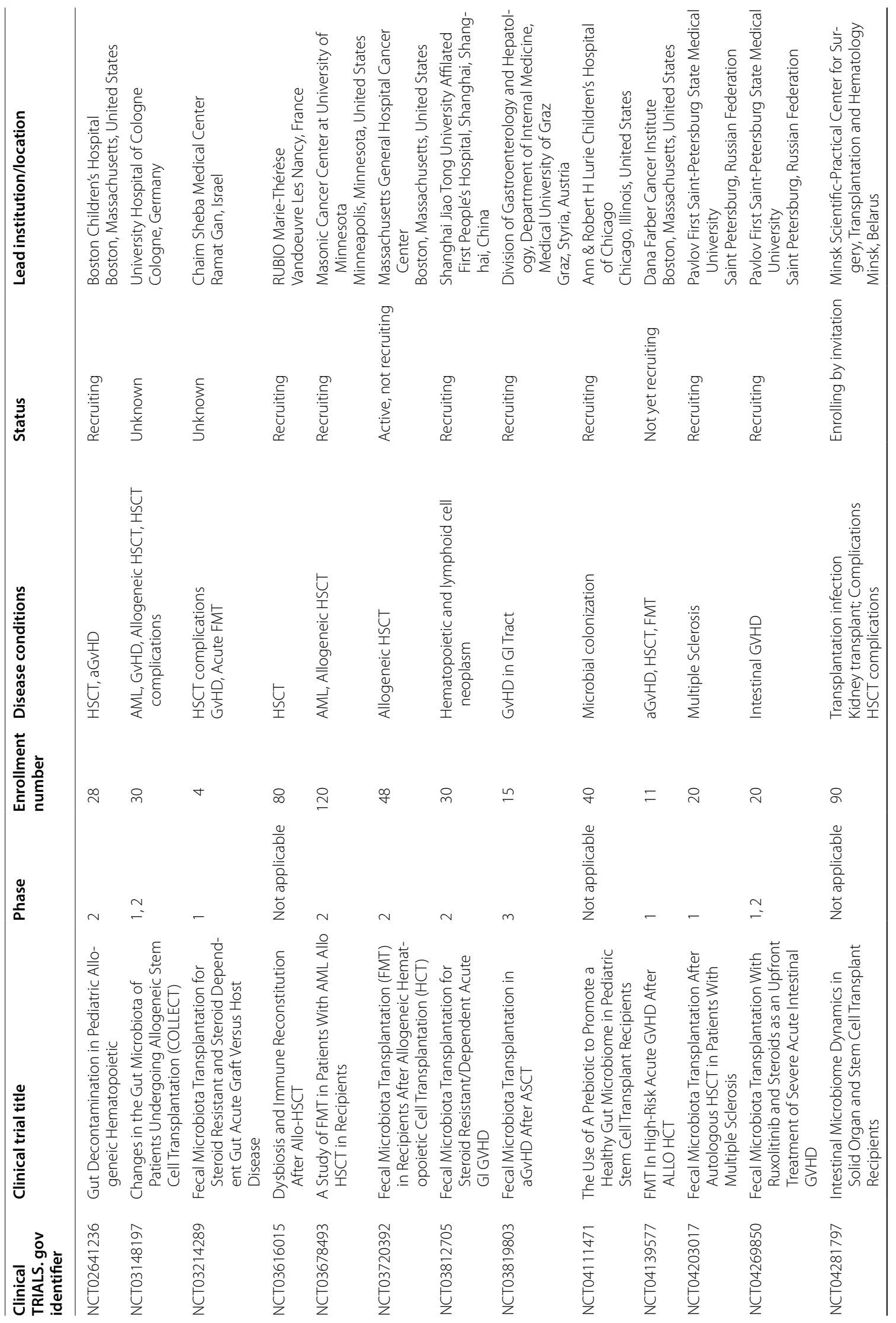




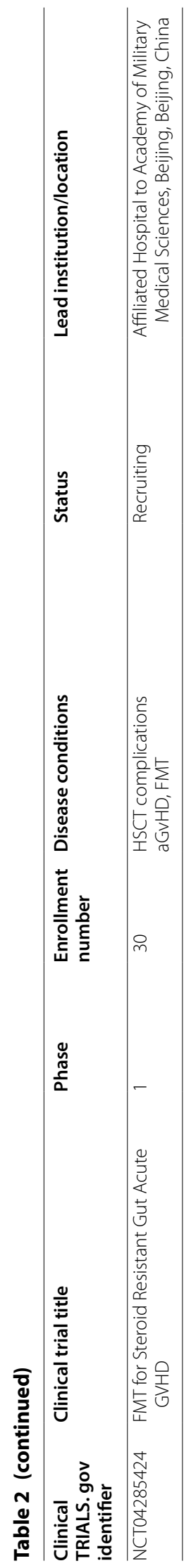


of a vital energy source. Other possible mechanism includes: protease activity inactivating secreted C. difficile toxins, stimulation of host-cell defenses through release of small molecules such as short-chain fatty acids, and direct activity against $\mathrm{C}$. difficile viability through bacteriocin-like mechanisms [90]. These potentially mechanisms of FMT against C. difficile remain to be fully elucidated and are summarized in Fig. 1.

\section{Antibiotics}

Antibiotics are another commonly used support option in GvHD patients. Based on the early results that GvHD is unlikely to occur in germ-free mice [92], GI decontamination using non-absorbable antibiotics was introduced in HSCT recipients. However, the mixed results were demonstrated by different studies [93, 94]. Recently, GM dynamics were analyzed in patients undergoing gut decontamination, comparing results in children receiving total or selective decontamination. In both groups, GM richness and diversity decreased markedly, but were restored gradually after cessation of antibiotics [95]. Using ciprofloxacin and metronidazole, or rifaximin only for gut decontamination, studies revealed a significant reduction in gut GvHD and 1 -year transplant related mortality, and a significant increase in overall survival, with less enterococcal load and higher urinary 3-indoxyl sulfate concentrations in the rifaximin group [96-98]. Furthermore, treatment of infectious complications with systemic antibiotics did not abrogate the beneficial effects of rifaximin on GM composition and on HSCT outcomes [99].

Though antibiotics have undoubtedly mitigated the risk of adverse outcomes attributed to infections, recent studies suggest that early broad-spectrum antibiotic use is an independent risk factor for increased mortality in allo-HSCT recipients $[19,100,101]$. Cumulative exposure to penicillin derivatives and carbapenem antibiotics was associated with a higher incidence rate of GI aGvHD [102]. In particular, piperacillin-tazobactam and imipenem-cilastatin were associated with increased incidence, severity, and mortality in gut GvHD [100], especially in patients receiving fourth-generation cephalosporins [103]. Recent study demonstrate that exposure to anaerobic antibiotics is associated with increased risks of acute gut/liver GvHD and acute GvHD mortality after allo-HSCT [104]. Recent Metaanalysis also confirmed that gut decontamination and prophylaxis with systemic antibiotics increase acute and intestinal GVHD, with a significant effect of microbiota diversity on treatment-related mortality and overall survival [105].

\section{Conclusion}

The advances of microbiome in HSCT enabled us to better understand the relationship between GM and GVHD, as well as the clinical treatment strategies of GM for GvHD patients. The clinical application of microbiota, as predictor of mortality in allo-HSCT and as therapeutic strategies with targeted modulation of GM, has been used for preventing or treating GM dysbiosis in patients with HSCT in the past years. However, there is still much work to be done in order to better comprehend the precise biological mechanism and the overall clinical impact of a specific dysbiosis pattern. With more advances with the possible microbiota-altering preventive and therapeutic strategies, the potential of modulating the microbiome to improve outcome of GvHD in patients with HSCT will come true soon.

\section{Abbreviations \\ aGvHD: Acute graft versus host disease; allo-HSCT: Allogeneic hematopoietic stem cell transplantation; AML: Acute myeloid leukemia; EN: Enteral nutrition; FAO: Food and Agriculture Organization of the United Nations; FMT: Fecal microbiota transplantation; Gl: Gastro-intestinal; GM: Gut microbiota; GvHD: Graft versus host disease; HDAC: Histone deacetylase; HSCT: Hematopoietic stem-cell transplantation; NEC: Necrotizing enterocolitis; rCDI: Recurrent or refractory Clostridium difficile infection; SCFA: Short-chain fatty acid; Tregs: Regulatory T cells; WHO: World Health Organization.}

\section{Acknowledgements}

We thank Dr. Delong Liu of New York Medical College and Dr. Peter Y.Z. Jiang of The Everett Clinic and Providence Regional Medical Center in USA for helpful discussion.

\section{Authors' contributions}

All authors contributed to drafting and revising the article and agree to be accountable for all aspects of the work. All authors read and approved the final manuscript.

\section{Funding}

This study was funded by the Key Scientific Research Project of Henan Provincial Education Department (20A320062), Jointly Sponsored Project of Henan Medical Science and Technology Research Plan of 2019 (LHGJ20190039) and Special Talents Project Fund of the First Affiliated Hospital of Zhengzhou University, Zhengzhou, China. The funding bodies did not participate in study design, in data collection, analysis, and interpretation, and in writing the manuscript.

\section{Availability of data and materials}

Not applicable.

Ethics approval and consent to participate

Not applicable.

\section{Consent for publication}

Not applicable.

\section{Competing interests}

The authors declare that they have no competing interests.

\section{Author details}

${ }^{1}$ Department of Hematology, The First Affiliated Hospital of Zhengzhou University, Zhengzhou 450052, China. ${ }^{2}$ Academy of Medical and Pharmaceutical Sciences of Zhengzhou University, Zhengzhou 450052, China. ${ }^{3}$ Department of Radiotherapy, The First Affiliated Hospital of Zhengzhou University, 
Zhengzhou 450052, China. ${ }^{4}$ The Affiliated Cancer Hospital of Zhengzhou University and Henan Cancer Hospital, Zhengzhou 450008, China.

Received: 2 October 2020 Accepted: 27 November 2020 Published online: 04 December 2020

\section{References}

1. The Integrative HMP (iHMP) Research Network Consortium. The Integrative Human Microbiome Project. Nature. 2019;569(7758):641-8.

2. Mazmanian SK, Liu CH, Tzianabos AO, Kasper DL. An immunomodulatory molecule of symbiotic bacteria directs maturation of the host immune system. Cell. 2005;122(1):107-18.

3. Karlsson FH, Tremaroli V, Nookaew I, Bergström G, Behre CJ, Fagerberg $B$, et al. Gut metagenome in European women with normal, impaired and diabetic glucose control. Nature. 2013;498(7452):99-103.

4. Abrahamsson TR, Jakobsson HE, Andersson AF, Björkstén B, Engstrand $L$, Jenmalm MC. Low gut microbiota diversity in early infancy precedes asthma at school age. Clin Exp Allergy. 2014;44(6):842-50.

5. Holler E, Butzhammer P, Schmid K, Hundsrucker C, Koestler J, Peter $\mathrm{K}$, et al. Metagenomic analysis of the stool microbiome in patients receiving allogeneic stem cell transplantation: loss of diversity is associated with use of systemic antibiotics and more pronounced in gastrointestinal graft-versus-host disease. Biol Blood Marrow Transplant. 2014;20(5):640-5.

6. Jenq RR, Ubeda C, Taur Y, Menezes CC, Khanin R, Dudakov JA, et al. Regulation of intestinal inflammation by microbiota following allogeneic bone marrow transplantation. J Exp Med. 2012;209(5):903-11.

7. Biagi E, Zama D, Nastasi C, Consolandi C, Fiori J, Rampelli S, et al. Gut microbiota trajectory in pediatric patients undergoing hematopoietic SCT. Bone Marrow Transplant. 2015:50(7):992-8.

8. Peled JU, Devlin SM, Staffas A, Lumish M, Khanin R, Littmann ER, et al. Intestinal microbiota and relapse after hematopoietic-cell transplantation. J Clin Oncol. 2017;35(15):1650-9.

9. Peled JU, Gomes ALC, Devlin SM, Littmann ER, Taur Y, Sung AD, et al. Microbiota as predictor of mortality in allogeneic hematopoietic-cell transplantation. N Engl J Med. 2020;382(9):822-34.

10. Zama $D$, Bossù $G$, Leardini $D$, Muratore $E$, Biagi $E$, Prete $A$, et al. Insights into the role of intestinal microbiota in hematopoietic stem-cell transplantation. Ther Adv Hematol. 2020;11:2040620719896961.

11. Magenau J, Runaas L, Reddy P. Advances in understanding the pathogenesis of graft-versus-host disease. Br J Haematol. 2016;173(2):190-205.

12. Washington $K$, Jagasia M. Pathology of graft-versus-host disease in the gastrointestinal tract. Hum Pathol. 2009;40(7):909-17.

13. Kambham N, Higgins JP, Sundram U, Troxell ML. Hematopoietic stem cell transplantation: graft versus host disease and pathology of gastrointestinal tract, liver, and lung. Adv Anat Pathol. 2014;21(5):301-20.

14. Belkaid Y, Hand TW. Role of the microbiota in immunity and inflammation. Cell. 2014;157(1):121-41.

15. Vinolo MA, Rodrigues HG, Nachbar RT, Curi R. Regulation of inflammation by short chain fatty acids. Nutrients. 2011;3(10):858-76.

16. Michonneau D, Latis E, Curis E, Dubouchet L, Ramamoorthy S, Ingram B, et al. Metabolomics analysis of human acute graft-versus-host disease reveals changes in host and microbiota-derived metabolites. Nat Commun. 2019;10(1):5695

17. Payen M, Nicolis I, Robin M, Michonneau D, Delannoye J, Mayeur C, et al. Functional and phylogenetic alterations in gut microbiome are linked to graft-versus-host disease severity. Blood Adv. 2020;4(9):1824-32.

18. Ouyang W, Kolls JK, Zheng Y. The biological functions of T helper 17 cell effector cytokines in inflammation. Immunity. 2008;28(4):454-67.

19. Taur Y, Jenq RR, Perales MA, Littmann ER, Morjaria S, Ling L, et al. The effects of intestinal tract bacterial diversity on mortality following allogeneic hematopoietic stem cell transplantation. Blood. 2014;124(7):1174-82.

20. Taur Y, Xavier JB, Lipuma L, Ubeda C, Goldberg J, Gobourne A, et al. Intestinal domination and the risk of bacteremia in patients undergoing allogeneic hematopoietic stem cell transplantation. Clin Infect Dis. 2012;55(7):905-14.
21. Lee SE, Lim JY, Ryu DB, Kim TW, Park SS, Jeon YW, et al. Alteration of the intestinal microbiota by broad-spectrum antibiotic use correlates with the occurrence of intestinal graft-versus-host disease. Biol Blood Marrow Transplant. 2019;25(10):1933-43.

22. Ferrara JL, Smith CM, Sheets J, Reddy P, Serody JS. Altered homeostatic regulation of innate and adaptive immunity in lower gastrointestinal tract GVHD pathogenesis. J Clin Invest. 2017;127(7):2441-51.

23. Chong PP, Koh AY. The gut microbiota in transplant patients. Blood Rev. 2020:39:100614

24. Han L, Zhang H, Chen S, Zhou L, Li Y, Zhao K, et al. Intestinal microbiota can predict acute graft-versus-host disease following allogeneic hematopoietic stem cell transplantation. Biol Blood Marrow Transplant. 2019;25(10):1944-55.

25. Han L, Zhao K, Li Y, Han H, Zhou L, Ma P, et al. A gut microbiota score predicting acute graft-versus-host disease following myeloablative allogeneic hematopoietic stem cell transplantation. Am J Transplant. 2020;20(4):1014-27.

26. Cotillard A, Kennedy SP, Kong LC, Prifti E, Pons N, Le Chatelier E, et al. Dietary intervention impact on gut microbial gene richness. Nature. 2013;500(7464):585-8.

27. Dao MC, Everard A, Aron-Wisnewsky J, Sokolovska N, Prifti E, Verger EO, et al. Akkermansia muciniphila and improved metabolic health during a dietary intervention in obesity: relationship with gut microbiome richness and ecology. Gut. 2016;65(3):426-36.

28. David LA, Maurice CF, Carmody RN, Gootenberg DB, Button JE, Wolfe $\mathrm{BE}$, et al. Diet rapidly and reproducibly alters the human gut microbiome. Nature. 2014;505(7484):559-63.

29. Krezalek MA, Yeh A, Alverdy JC, Morowitz M. Influence of nutrition therapy on the intestinal microbiome. Curr Opin Clin Nutr Metab Care. 2017;20(2):131-7.

30. Liou AP, Paziuk M, Luevano JM Jr., Machineni S, Turnbaugh PJ, Kaplan LM. Conserved shifts in the gut microbiota due to gastric bypass reduce host weight and adiposity. Sci Transl Med. 2013;5(178):178ra41.

31. Mack I, Penders J, Cook J, Dugmore J, Mazurak N, Enck P. Is the impact of starvation on the gut microbiota specific or unspecific to anorexia nervosa? A narrative review based on a systematic literature search. Curr Neuropharmacol. 2018;16(8):1131-49.

32. Seitz J, Belheouane M, Schulz N, Dempfle A, Baines JF, Herpertz-Dahlmann $B$. The impact of starvation on the microbiome and gut-brain interaction in anorexia nervosa. Front Endocrinol. 2019:10:41.

33. Jenq RR, Taur Y, Devlin SM, Ponce DM, Goldberg JD, Ahr KF, et al. Intestinal blautia is associated with reduced death from graft-versus-host disease. Biol Blood Marrow Transplant. 2015;21(8):1373-83.

34. MacFie J, Reddy BS, Gatt M, Jain PK, Sowdi R, Mitchell CJ. Bacterial translocation studied in 927 patients over 13 years. Br J Surg 2006;93(1):87-93.

35. Pierre JF. Gastrointestinal immune and microbiome changes during parenteral nutrition. Am J Physiol Gastrointest Liver Physiol. 2017;312(3):G246-56

36. Ríos-Covián D, Ruas-Madiedo P, Margolles A, Gueimonde M, de Los Reyes-Gavilán CG, Salazar N. Intestinal short chain fatty acids and their link with diet and human health. Front Microbiol. 2016;7:185.

37. Azarnoush S, Bruno B, Beghin L, Guimber D, Nelken B, Yakoub-Agha I, et al. Enteral nutrition: a first option for nutritional support of children following allo-SCT? Bone Marrow Transplant. 2012;47(9):1191-5.

38. Gonzales F, Bruno B, Alarcón Fuentes M, De Berranger E, Guimber D, Behal $\mathrm{H}$, et al. Better early outcome with enteral rather than parenteral nutrition in children undergoing MAC allo-SCT. Clin Nutr. 2018;37(6 Pt A):2113-21.

39. Guièze R, Lemal R, Cabrespine A, Hermet E, Tournilhac O, Combal C, et al. Enteral versus parenteral nutritional support in allogeneic haematopoietic stem-cell transplantation. Clin Nutr. 2014;33(3):533-8.

40. Seguy D, Duhamel A, Rejeb MB, Gomez E, Buhl ND, Bruno B, et al. Better outcome of patients undergoing enteral tube feeding after myeloablative conditioning for allogeneic stem cell transplantation. Transplantation. 2012;94(3):287-94.

41. Zama D, Muratore E, Biagi E, Forchielli ML, Rondelli R, Candela M, et al. Enteral nutrition protects children undergoing allogeneic hematopoietic stem cell transplantation from blood stream infections. Nutr J. 2020;19(1):29. 
42. D'Amico F, Biagi E, Rampelli S, Fiori J, Zama D, Soverini M, et al. Enteral nutrition in pediatric patients undergoing hematopoietic SCT promotes the recovery of gut microbiome homeostasis. Nutrients. 2019;11(12):2958.

43. Gibson GR, Hutkins R, Sanders ME, Prescott SL, Reimer RA, Salminen SJ, et al. Expert consensus document: The International Scientific Association for Probiotics and Prebiotics (ISAPP) consensus statement on the definition and scope of prebiotics. Nat Rev Gastroenterol Hepatol. 2017;14(8):491-502.

44. Shono Y, van den Brink MRM. Gut microbiota injury in allogeneic haematopoietic stem cell transplantation. Nat Rev Cancer. 2018;18(5):283-95.

45. Tavil B, Koksal E, Yalcin SS, Uckan D. Pretransplant nutritional habits and clinical outcome in children undergoing hematopoietic stem cell transplant. Exp Clin Transplant. 2012;10(1):55-61.

46. Iyama S, Sato T, Tatsumi H, Hashimoto A, Tatekoshi A, Kamihara Y, et al. Efficacy of enteral supplementation enriched with glutamine, fiber, and oligosaccharide on mucosal injury following hematopoietic stem cell transplantation. Case Rep Oncol. 2014;7(3):692-9.

47. Severyn CJ, Brewster R, Andermann TM. Microbiota modification in hematology: still at the bench or ready for the bedside? Blood Adv. 2019:3(21):3461-72.

48. Smith PM, Howitt MR, Panikov N, Michaud M, Gallini CA, Bohlooly YM, et al. The microbial metabolites, short-chain fatty acids, regulate colonic Treg cell homeostasis. Science. 2013;341(6145):569-73.

49. Kaisar MMM, Pelgrom LR, van der Ham AJ, Yazdanbakhsh M, Everts B. Butyrate conditions human dendritic cells to prime type 1 regulatory $T$ cells via both histone deacetylase inhibition and $\mathrm{g}$ protein-coupled receptor 109A signaling. Front Immunol. 2017;8:1429.

50. Qin Y, Wade PA. Crosstalk between the microbiome and epigenome: messages from bugs. J Biochem. 2018;163(2):105-12.

51. Schulthess J, Pandey S, Capitani M, Rue-Albrecht KC, Arnold I, Franchini $F$, et al. The short chain fatty acid butyrate imprints an antimicrobial program in macrophages. Immunity. 2019;50(2):432-45.e7.

52. Schoener CA, Carillo-Conde B, Hutson HN, Peppas NA. An inulin and doxorubicin conjugate for improving cancer therapy. J Drug Deliv Sci Technol. 2013;23(2):111-8.

53. Conserva MR, Anelli L, Zagaria A, Specchia G, Albano F. The pleiotropic role of retinoic acid/retinoic acid receptors signaling: from vitamin a metabolism to gene rearrangements in acute promyelocytic leukemia. Int J Mol Sci. 2019;20(12):2921.

54. Lounder DT, Khandelwal P, Dandoy CE, Jodele S, Grimley MS, Wallace $\mathrm{G}$, et al. Lower levels of vitamin A are associated with increased gastrointestinal graft-versus-host disease in children. Blood. 2017;129(20):2801-7.

55. Grizotte-Lake M, Zhong G, Duncan K, Kirkwood J, Iyer N, Smolenski I, et al. Commensals suppress intestinal epithelial cell retinoic acid synthesis to regulate interleukin-22 activity and prevent microbial dysbiosis. Immunity. 2018;49(6):1103-15.e6.

56. Lounder DT, Khandelwal P, Gloude NJ, Dandoy CE, Jodele S, Medvedovic M, et al. Interleukin-22 levels are increased in gastrointestinal graft-versus-host disease in children. Haematologica. 2018;103(10):e480-2.

57. Superti F. Lactoferrin from bovine milk: a protective companion for life. Nutrients. 2020;12(9):2562.

58. Drago-Serrano ME, Campos-Rodriguez R, Carrero JC, de la Garza M. Lactoferrin and peptide-derivatives: antimicrobial agents with potential use in nonspecific immunity modulation. Curr Pharm Des. 2018;24(10):1067-78.

59. Haiwen Z, Rui H, Bingxi Z, Qingfeng G, Jifeng Z, Xuemei W, et al. Oral Administration of bovine lactoferrin-derived lactoferricin (Lfcin) B could attenuate enterohemorrhagic Escherichia coli O157:H7 induced intestinal disease through improving intestinal barrier function and microbiota. J Agric Food Chem. 2019;67(14):3932-45.

60. Inoue M, Okamura T, Yasui M, Sakata N, Yagi K, Kawa K. Lactoferrin for gut GVHD. Bone Marrow Transplant. 2001;28(11):1091-2.

61. Meyer MP, Chow SSW, Alsweiler J, Bourchier D, Broadbent R, Knight $D$, et al. Probiotics for prevention of severe necrotizing enterocolitis: experience of New Zealand neonatal intensive care units. Front Pediatr. 2020;8:119.
62. Ochoa TJ, Loli S, Mendoza K, Carcamo C, Bellomo S, Cam L, et al. Effect of bovine lactoferrin on prevention of late-onset sepsis in infants < 1500g: a pooled analysis of individual patient data from two randomized controlled trials. Biochem Cell Biol. 2020. https://doi. org/10.1139/bcb-2020-0046.

63. Yamaguchi T, Konishi H, Aoki K, Ishii Y, Chono K, Tateda K. The gut microbiome diversity of Clostridioides difficile-inoculated mice treated with vancomycin and fidaxomicin. J Infect Chemother. 2020;26(5):483-91.

64. van der Velden WJ, Blijlevens NM, Donnelly JP. The potential role of lactoferrin and derivatives in the management of infectious and inflammatory complications of hematology patients receiving a hematopoietic stem cell transplantation. Transpl Infect Dis. 2008;10(2):80-9.

65. Elzoghby AO, Abdelmoneem MA, Hassanin IA, Abd Elwakil MM, Elnaggar MA, Mokhtar S, et al. Lactoferrin, a multi-functional glycoprotein: active therapeutic, drug nanocarrier \& targeting ligand. Biomaterials. 2020;263:120355.

66. Hill C, Guarner F, Reid G, Gibson GR, Merenstein DJ, Pot B, et al. Expert consensus document. The International Scientific Association for Probiotics and Prebiotics consensus statement on the scope and appropriate use of the term probiotic. Nat Rev Gastroenterol Hepatol. 2014;11(8):506-14.

67. Gorshein E, Wei C, Ambrosy S, Budney S, Vivas J, Shenkerman A, et al. Lactobacillus rhamnosus $\mathrm{GG}$ probiotic enteric regimen does not appreciably alter the gut microbiome or provide protection against GVHD after allogeneic hematopoietic stem cell transplantation. Clin Transplant. 2017. https://doi.org/10.1111/ctr.12947.

68. Sharma A, Tilak T, Bakhshi S, Raina V, Kumar L, Chaudhary SP, et al. Lactobacillus brevis CD2 lozenges prevent oral mucositis in patients undergoing high dose chemotherapy followed by haematopoietic stem cell transplantation. ESMO Open. 2016;1 (6):e000138.

69. Sadanand A, Newland JG, Bednarski JJ. Safety of probiotics among high-risk pediatric hematopoietic stem cell transplant recipients. Infect Dis Ther. 2019;8(2):301-6.

70. Mehta A, Rangarajan S, Borate U. A cautionary tale for probiotic use in hematopoietic SCT patients-Lactobacillus acidophilus sepsis in a patient with mantle cell lymphoma undergoing hematopoietic SCT. Bone Marrow Transplant. 2013;48(3):461-2.

71. Robin F, Paillard C, Marchandin H, Demeoca F, Bonnet R, Hennequin C. Lactobacillus rhamnosus meningitis following recurrent episodes of bacteremia in a child undergoing allogeneic hematopoietic stem cell transplantation. J Clin Microbiol. 2010;48(11):4317-9.

72. Cohen SA, Woodfield MC, Boyle N, Stednick Z, Boeckh M, Pergam SA. Incidence and outcomes of bloodstream infections among hematopoietic cell transplant recipients from species commonly reported to be in over-the-counter probiotic formulations. Transpl Infect Dis. 2016;18(5):699-705.

73. Ladas EJ, Bhatia M, Chen L, Sandler E, Petrovic A, Berman DM, et al. The safety and feasibility of probiotics in children and adolescents undergoing hematopoietic cell transplantation. Bone Marrow Transplant. 2016;51(2):262-6.

74. Rao K, Safdar N. Fecal microbiota transplantation for the treatment of Clostridium difficile infection. J Hosp Med. 2016;11(1):56-61.

75. Cammarota G, laniro G, Tilg H, Rajilić-Stojanović M, Kump P, Satokari R, et al. European consensus conference on faecal microbiota transplantation in clinical practice. Gut. 2017;66(4):569-80.

76. DeFilipp Z, Hohmann E, Jeng RR, Chen YB. Fecal microbiota transplantation: restoring the injured microbiome after allogeneic hematopoietic cell transplantation. Biol Blood Marrow Transplant. 2019;25(1):e17-22.

77. Ouyang J, Isnard S, Lin J, Fombuena B, Peng X, Nair Parvathy S, et al. Treating from the inside out: relevance of fecal microbiota transplantation to counteract gut damage in GVHD and HIV infection. Front Med. 2020;7:421.

78. DeFilipp Z, Peled JU, Li S, Mahabamunuge J, Dagher Z, Slingerland AE, et al. Third-party fecal microbiota transplantation following allo-HCT reconstitutes microbiome diversity. Blood Adv. 2018;2(7):745-53.

79. van Lier YF, Davids M, Haverkate NJE, de Groot PF, Donker ML, Meijer E, et al. Donor fecal microbiota transplantation ameliorates intestinal graft-versus-host disease in allogeneic hematopoietic cell transplant recipients. Sci Transl Med. 2020;12(556):eaaz8926.

80. Wang Q, Fu YW, Wang YQ, Ai H, Yuan FF, Wei XD, et al. Fecal microbiota transplantation for patients with refractory diarrhea after allogeneic 
hematopoietic stem cell transplantation. Zhonghua Xue Ye Xue Za Zhi. 2019;40(10):853-5.

81. Galloway-Peña JR, Peterson CB, Malik F, Sahasrabhojane PV, Shah DP, Brumlow CE, et al. Fecal microbiome, metabolites, and stem cell transplant outcomes: a single-center pilot study. Open Forum Infect Dis. 2019;6(5):ofz173.

82. Battipaglia G, Malard F, Rubio MT, Ruggeri A, Mamez AC, Brissot E, et al. Fecal microbiota transplantation before or after allogeneic hematopoietic transplantation in patients with hematologic malignancies carrying multidrug-resistance bacteria. Haematologica. 2019;104(8):1682-8.

83. Biernat MM, Urbaniak-Kujda D, Dybko J, Kapelko-Słowik K, Prajs I, Wróbel T. Fecal microbiota transplantation in the treatment of intestinal steroid-resistant graft-versus-host disease: two case reports and a review of the literature. J Int Med Res. 2020;48(6):300060520925693.

84. Qi X, Li X, Zhao Y, Wu X, Chen F, Ma X, et al. Treating steroid refractory intestinal acute graft-vs.-host disease with fecal microbiota transplantation: a pilot study. Front Immunol. 2018;9:2195.

85. Biagi E, Zama D, Rampelli S, Turroni S, Brigidi P, Consolandi C, et al. Early gut microbiota signature of aGvHD in children given allogeneic hematopoietic cell transplantation for hematological disorders. BMC Med Genomics. 2019;12(1):49.

86. Ramai D, Zakhia K, Ofosu A, Ofori E, Reddy M. Fecal microbiota transplantation: donor relation, fresh or frozen, delivery methods, costeffectiveness. Ann Gastroenterol. 2019;32(1):30-8.

87. Jiang ZD, Jeng RR, Ajami NJ, Petrosino JF, Alexander AA, Ke S, et al. Safety and preliminary efficacy of orally administered lyophilized fecal microbiota product compared with frozen product given by enema for recurrent Clostridium difficile infection: a randomized clinical trial. PLoS ONE. 2018;13(11):e0205064.

88. Wardill HR, Secombe KR, Bryant RV, Hazenberg MD, Costello SP. Adjunctive fecal microbiota transplantation in supportive oncology: emerging indications and considerations in immunocompromised patients. EBioMedicine. 2019;44:730-40.

89. Doki N, Suyama M, Sasajima S, Ota J, Igarashi A, Mimura I, et al. Clinical impact of pre-transplant gut microbial diversity on outcomes of allogeneic hematopoietic stem cell transplantation. Ann Hematol. 2017:96(9):1517-23.

90. Gupta S, Allen-Vercoe E, Petrof EO. Fecal microbiota transplantation: in perspective. Therap Adv Gastroenterol. 2016;9(2):229-39.

91. Kelly CR, Kahn S, Kashyap P, Laine L, Rubin D, Atreja A, et al. Update on Fecal Microbiota Transplantation 2015: indications, methodologies, mechanisms, and outlook. Gastroenterology. 2015;149(1):223-37.

92. van Bekkum DW, Roodenburg J, Heidt PJ, van der Waaij D. Mitigation of secondary disease of allogeneic mouse radiation chimeras by modification of the intestinal microflora. J Natl Cancer Inst. 1974;52(2):401-4.

93. Navari RM, Buckner CD, Clift RA, Storb R, Sanders JE, Stewart P, et al. Prophylaxis of infection in patients with aplastic anemia receiving allogeneic marrow transplants. Am J Med. 1984;76(4):564-72.
94. Vossen JM, Heidt PJ, van den Berg H, Gerritsen EJ, Hermans J, Dooren LJ. Prevention of infection and graft-versus-host disease by suppression of intestinal microflora in children treated with allogeneic bone marrow transplantation. Eur J Clin Microbiol Infect Dis. 1990;9(1):14-23.

95. Bekker V, Zwittink RD, Knetsch CW, Sanders I, Berghuis D, Heidt PJ, et al. Dynamics of the gut microbiota in children receiving selective or total gut decontamination treatment during hematopoietic stem cell transplantation. Biol Blood Marrow Transplant. 2019;25(6):1164-71.

96. Ponziani FR, Zocco MA, D'Aversa F, Pompili M, Gasbarrini A. Eubiotic properties of rifaximin: disruption of the traditional concepts in gut microbiota modulation. World J Gastroenterol. 2017;23(25):4491-9.

97. Lopetuso LR, Petito V, Scaldaferri F, Gasbarrini A. Gut microbiota modulation and mucosal immunity: focus on rifaximin. Mini Rev Med Chem. 2015;16(3):179-85.

98. Townsend CM, Parker CE, MacDonald JK, Nguyen TM, Jairath V, Feagan $\mathrm{BG}$, et al. Antibiotics for induction and maintenance of remission in Crohn's disease. Cochrane Database Syst Rev. 2019;2(2):cd012730.

99. Weber D, Oefner PJ, Dettmer K, Hiergeist A, Koestler J, Gessner A, et al. Rifaximin preserves intestinal microbiota balance in patients undergoing allogeneic stem cell transplantation. Bone Marrow Transplant. 2016;51(8):1087-92.

100. Shono Y, Docampo MD, Peled JU, Perobelli SM, Velardi E, Tsai JJ, et al. Increased GVHD-related mortality with broad-spectrum antibiotic use after allogeneic hematopoietic stem cell transplantation in human patients and mice. Sci Transl Med. 2016;8(339):339ra71.

101. Kumari R, Palaniyandi S, Hildebrandt GC. Microbiome: an emerging new frontier in graft-versus-host disease. Dig Dis Sci. 2019;64(3):669-77.

102. Farowski F, Bücker V, Vehreschild JJ, Biehl L, Cruz-Aguilar R, Scheid C, et al. Impact of choice, timing, sequence and combination of broadspectrum antibiotics on the outcome of allogeneic haematopoietic stem cell transplantation. Bone Marrow Transplant. 2018:53(1):52-7.

103. Nishi K, Kanda J, Hishizawa M, Kitano T, Kondo T, Yamashita K, et al. Impact of the use and type of antibiotics on acute graft-versus-host disease. Biol Blood Marrow Transplant. 2018;24(11):2178-83.

104. Tanaka JS, Young RR, Heston SM, Jenkins K, Spees LP, Sung AD, et al. Anaerobic antibiotics and the risk of graft-versus-host disease after allogeneic hematopoietic stem cell transplantation. Biol Blood Marrow Transplant. 2020;26:2053-60.

105. Gavriilaki M, Sakellari I, Anagnostopoulos A, Gavriilaki E. The impact of antibiotic-mediated modification of the intestinal microbiome on outcomes of allogeneic hematopoietic cell transplantation: systematic review and meta-analysis. Biol Blood Marrow Transplant. 2020;26(9):1738-46.

\section{Publisher's Note}

Springer Nature remains neutral with regard to jurisdictional claims in published maps and institutional affiliations.

\footnotetext{
Ready to submit your research? Choose BMC and benefit from:

- fast, convenient online submission

- thorough peer review by experienced researchers in your field

- rapid publication on acceptance

- support for research data, including large and complex data types

- gold Open Access which fosters wider collaboration and increased citations

- maximum visibility for your research: over 100M website views per year
}

At BMC, research is always in progress.

Learn more biomedcentral.com/submissions 